\title{
Von Brunn's Nest in an Incidental Bladder Mass Found during Holmium Laser Enucleation of the Prostate
}

\author{
Seungsoo Lee \\ Department of Urology, Pusan National University Yangsan Hospital, Yangsan, Korea
}

\begin{abstract}
A 62-year-old male with benign prostatic hyperplasia underwent holmium laser enucleation of the prostate. During surgery, a small nodular mass was found incidentally in the trigone of the bladder. The lesion was removed completely by a transurethral resection with a bipolar device. A pathology examination of the lesion indicated von Brunn's nests.
\end{abstract}

Keywords: Urinary bladder neoplasms; Inflammation; Cystitis; Transurethral resection of prostate

Copyright $\subset$ 2020, Korean Association of Urogenital Tract Infection and Inflammation. All rights reserved. (i) (\$) This is an open access article distributed under the terms of the Creative Commons Attribution Non-Commercial License (http://creativecommons.org/licenses/by-nc/4.0) which permits unrestricted non-commercial use, distribution, and reproduction in any medium, provided the original work is properly cited.

\author{
Received: 27 December, 2019 \\ Revised: 7 February, 2020 \\ Accepted: 14 April, 2020
}

\author{
Correspondence to: Seungsoo Lee \\ (iD) https://orcid.org/0000-0001-7856-6766 \\ Department of Urology, Pusan National University \\ Yangsan Hospital, 20 Geumo-ro, Mulgeum-eup, \\ Yangsan 50612, Korea \\ Tel: +82-55-360-2134, Fax: +82-55-360-2164 \\ E-mail: slee128@hanmail.net
}

Cystoscopy is a useful diagnostic method for examining the inside of the bladder. Cystoscopy is generally performed when a patient has urinary symptoms, such as hematuria, dysuria, and suprapubic pain. On the other hand, bladder masses are sometimes detected incidentally during other examinations or surgery. In this case, it is important to distinguish between cancer and benign or inflammatory lesions by a pathology examination. This paper reports a case of a patient with an incidental bladder mass that was diagnosed as a von Brunn's nest during holmium laser enucleation of the prostate (HoLEP).

\section{CASE REPORT}

A 62-year-old male visited for lower urinary symptoms, including weak stream and frequent voiding. At a local urology clinic, the serum level of prostate-specific antigen (PSA) was checked, and transrectal ultrasound was performed. The PSA level and prostate volume were 5.32 $\mathrm{ng} / \mathrm{ml}$ and $45 \mathrm{ml}$, respectively. The patient had been treated for a duodenal ulcer and was taking medication for hypertension and hyperlipidemia.
The patient visited the urologic clinic and underwent a prostate biopsy, which indicated nodular hyperplasia. Serum and urine laboratory tests indicated the following: serum level of white blood cells (WBCs), red blood cells (RBCs), and hemoglobin of $6,660 / \mu \mathrm{l}, 5.39 \times 10^{6} / \mu \mathrm{l}$, and $16.2 \mathrm{~g} / \mathrm{dl}$, respectively. The serum levels of aspartate aminotransferase, alanine aminotransferase, blood urea nitrogen, and creatinine were $29 \mathrm{IU} / \mathrm{L}, 30 \mathrm{IU} / \mathrm{L}, 13.6 \mathrm{mg} / \mathrm{dl}$, and $0.90 \mathrm{mg} / \mathrm{dl}$, respectively. The prothrombin time, international normalized ratio, and activated partial thromboplastin time were 12.4 seconds, was 0.95 , and 36.8 seconds, respectively. The urinary RBC count and urinary WBC count was $>30 / \mathrm{HPF}$ (high power field) and 3-5/HPF, respectively.

The patient underwent HoLEP surgery for benign prostatic hyperplasia. Under general anesthesia, a 26 Fr resectoscope was inserted into the urethra and bladder. During the bladder examination, a nodular mass was found incidentally in the trigone of the bladder. The size of the mass was approximately $1 \mathrm{~cm}$ in diameter (Fig. 1). A 22 Fr cystoscope with a loop was inserted into the bladder. The incidental trigone mass was resected completely using a bipolar electrosurgical unit. After resecting the mass, HoLEP was 


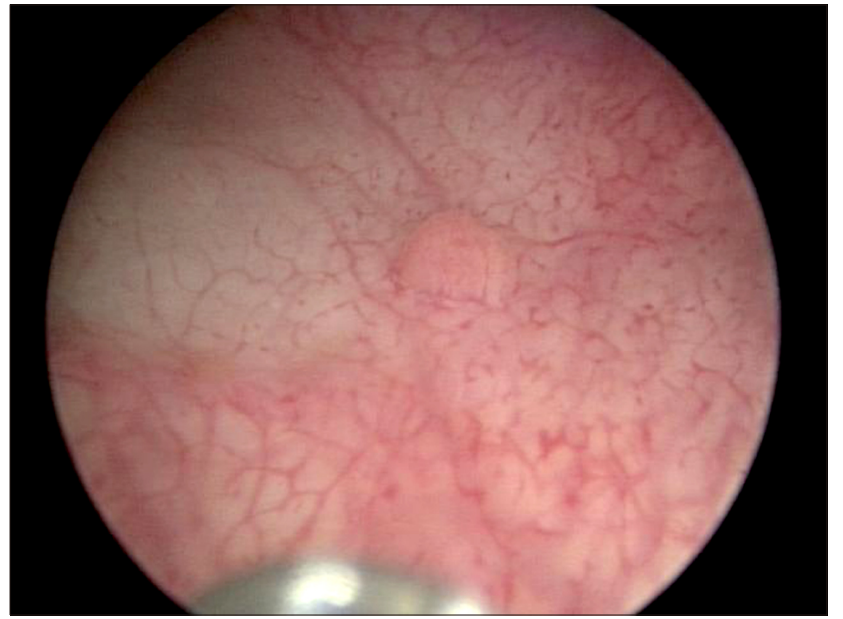

Fig. 1. A nodular mass was found incidentally in the trigone of the bladder.

performed.

A pathology examination of the mass revealed the proliferation of von Brunn's nests (Fig. 2). After surgery, voiding symptoms of the patient were resolved, and he did not complain of hematuria or bladder pain without medication

\section{DISCUSSION}

Some papers have reported the diagnosis of von Brunn's nests after the transurethral resection of a bladder mass. The masses, in those cases, were suspected of being bladder cancer during a preoperative examination, including cystoscopy and a computed tomography scan [1-3]. This is the first report of an incidental bladder mass indicated as von Brunn's during HoLEP surgery.

Von Brunn's nests are groups of proliferating epithelial cells commonly found in the adult lower urinary tract. They are one of the most common proliferating lesions in the bladder and include cystitis cystica and cystitis glandularis [4,5]. Von Brunn's nests are generally observed in the normal urothelial mucosa and are believed to be caused by the invagination of normal urothelium in the lamina propria. Von Brunn's nests can be seen in $89 \%$ of normal bladder mucosa [1,4].

Von Brunn's nests are usually located on the superficial layer of the lamina propria. They are regular in shape and have smooth edges. In addition, they have a relatively identical lesion depth and lack nuclear atypia $[1,5,6]$. These

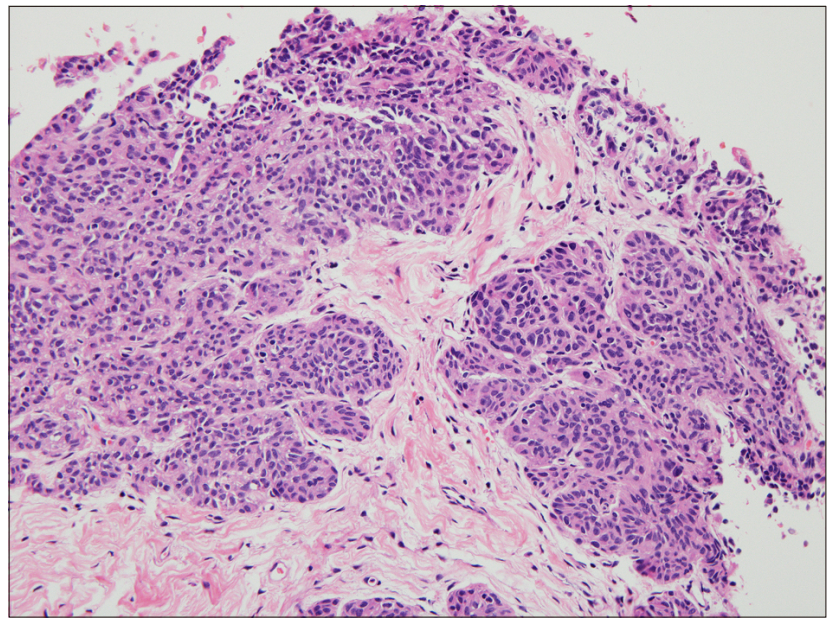

Fig. 2. Photomicroscopy image (H\&E stain, $\times 200)$ of von Brunn's nests.

lesions can sometimes be confused with nested variants of invasive urothelial carcinoma if the von Brunn's nests are so hyperplastic or florid that they can form significant solid cell nodules, or if they are located in the deep layer of the lamina propria and have an irregular basal layer of cells [7].

These lesions are clinically important because they can result in hematuria and voiding difficulty due to obstruction of the mass. Moreover, they can be misdiagnosed as bladder cancer during cystoscopy [1,2]. Large lesions can be detected by computed tomography or intravenous urography [2].

Of significant relevance is the similarity of the florid proliferation of von Brunn's nests to the nested variant of transitional cell carcinoma (NVTCC). NVTCC is a rare tumor with an incidence of only $0.3 \%$ of invasive bladder tumors and is characterized by an unusual, bland morphology on microscopy. Patients with the florid proliferation of von Brunn's nests show larger nests of cells with a regular shape and spacing compared to smaller, irregular nests of NVTCC with irregular spacing and infiltrative base. The presence of a muscularis propria invasion is a key distinguishing feature. This may not be present in early lesions, and the bland cytology of this tumor can prove challenging when only lamina propria invasion is present $[1,8]$.

Therefore, a biopsy is essential to ensure an accurate diagnosis with von Brunn's nests. A complete resection of an incidental bladder mass might be needed to distinguish von Brunn's nests and bladder cancer. 


\section{CONFLICT OF INTEREST}

No potential conflict of interest relevant to this article was reported.

\section{REFERENCES}

1. Volmar KE, Chan TY, De Marzo AM, Epstein JI. Florid von Brunn nests mimicking urothelial carcinoma: a morphologic and immunohistochemical comparison to the nested variant of urothelial carcinoma. Am J Surg Pathol 2003;27:1243-52.

2. Kim HS, Kwak JE, Shim SH, Joo M, Chang SH, Chi JG, et al. Florid von Brunn nests of the urinary bladder - a case report -. Korean J Pathol 2008;42:169-71.

3. Lee $\mathrm{JH}$, Byun $\mathrm{KH}$, Jeon JM. Brunn nests masquerading as bladder tumor: a case report. J Korean Radiol Soc 2005;52:
409-12.

4. Jones EC. Urinary bladder. Mimics of neoplasia and new pathologic entities. Urol Clin North Am 1999;26:509-34, vi.

5. Wiener DP, Koss LG, Sablay B, Freed SZ. The prevalence and significance of Brunn's nests, cystitis cystica and squamous metaplasia in normal bladders. J Urol 1979;122:317-21.

6. Young RH. Non-neoplastic disorders of the urinary bladder. In: Bostwick DG, Cheng L, editors. Urologic surgical pathology. 2nd ed. St. Louis: Elsevier Mosby; 2008. p. 215-56.

7. Guo A, Liu A, Teng X. The pathology of urinary bladder lesions with an inverted growth pattern. Chin J Cancer Res 2016;28: 107-21.

8. Nekkanti S, Doering A, Zynger DL, Hundley AF. von Brunn's nests and follicular cystitis following intradetrusor onabotulinumtoxinA injections for overactive bladder. Urol Case Rep 2017;14:38-41. 